\title{
Resection Arthroplasty of the Upper Extremity
}

K. Tillmann ${ }^{\dagger}$ Bad Bramstedt

M. Russlies Lübeck

M. Ockert Bad Bramstedt

B. Greitemann Bad Rothenfelde 
Tillmann ${ }^{\dagger}$, Karl, Prof. Dr. med.

Klingbarg 5

DE-24576 Bad Bramstedt (Germany)

E-Mail karl.tillmann@googlemail.com

Russlies, Martin, Prof. Dr. med.

Sektion für Orthopädie

Ratzeburger Allee 160

DE-23562 Lübeck (Germany)

E-Mailmartin.russlies@uk-sh.de
Ockert, Michael, Dipl. math.

Dramburger Weg 9

DE-24576 Bad Bramstedt (Germany)

E-Mail powerocks@aol.com
Greitemann, Bernhard, Prof. Dr. med. RehaKlinikum Bad Rothenfelde

Klinik Münsterland

Auf der Stöwwe 11

DE-49214 Bad Rothenfelde (Germany)

E-Mail greitemann@klinik muensterland.de

\section{Disclosure Statement}

The authors have no conflicts of interest to disclose.

All rights reserved.

This article is licensed under the Creative Commons Attribution-NonCommercial-NoDerivatives 4.0 International License (CC BY-NC-ND) (http://www.karger.com/Services/OpenAccessLicense). Usage and distribution for commercial purposes as well as any distribution of modified material requires written permission.

(c) 2018 The Author(s). Published by S. Karger AG, Basel

P.O. Box, $\mathrm{CH}-4009$ Basel (Switzerland) 


\section{Contents}

\section{Introduction}

1.1 References

\section{Glenohumeral Joint}

2.1 Resection Arthroplasty of the Glenohumeral Joint (Shoulder Joint)

2.1.1 Indication and Development

2.1.2 Surgical Technique

2.1.3 Follow-Up Treatment

2.1.4 Complications

2.1.5 Results

2.1.6 Discussion

2.1.7 References

\section{Clavicular Joints}

103.1 Resection Arthroplasty of the Acromioclavicular Joint (Shoulder Level)

3.1.1 Surgical Technique

3.1.2 Follow-Up Treatment and Rehabilitation

3.2 Resection Arthroplasty of the Sternoclavicular Joint (Breastbone-Collarbone)

3.2.1 Surgical Technique

3.2.2 Follow-Up Treatment and Rehabilitation

3.2.3 References

\section{Elbow}

$14 \quad 4.1$ Resection Arthroplasty of the Elbow Joint 1969-1989

4.1.1 Surgical Technique (1969-1989)

4.1.2 Follow-Up Treatment

4.1.3 Results

4.2 Resection, Interposition and Suspension Arthroplasty of the Elbow Joint (as of 1990)

4.2.1 Surgical Technique

4.2.2 Follow-Up Treatment

4.2.3 Results

4.2.4 Assessment

4.2.5 References 


\section{Hand}

5.1 Resection Arthroplasty of the Wrist

5.1.1 Surgical Technique

5.1.2 Specific Features

5.1.3 Results

5.1.4 References

5.2 Resection Arthroplasty of the Trapeziometacarpal Joint

5.2.1 Surgical Technique

5.2.2 Follow-Up Treatment

5.2.3 Specific Features

5.2.4 Results

5.2.5 References

5.3 MCP II-V Resection Arthroplasty

5.3.1 Pathomechanism

5.3.2 Surgical Technique

5.3.3 Follow-Up Treatment and Rehabilitation

5.3.4 Results

5.3.5 References

436 A Retrospective View - A Critical Assessment 


\section{Editorial Note}

Professor Tillmann approached us in 2016. He had written a text which draws attention to the advantages offered by resection arthroplasty in upper extremity surgery and was looking for a publisher. His text represents a summary and a documentation of his life's work.

It was important to Professor Tillmann that the surgical techniques he had developed and promoted would not be forgotten. He realized that it was possible to achieve superior outcomes using excision arthroplasty even though the degree of attention paid to this approach had in recent years been in decline. A reduced risk of infection and reduced vulnerability to wear and tear or loosening are just two of the important arguments Professor Tillmann presents in favor of nonalloplastic restoration.

Our decision to publish his manuscript had not been a difficult one, but in the end the project spread over quite a long period of time. The first step involved having the text translated into English. We had many in-depth discussions with Professor Tillmann and worked closely with him in the process to get this text ready for publication. We are glad that we did eventually manage to achieve our goal even though it was just few months before he sadly passed away. 